\title{
Azithromycin attenuates airway inflammation in a mouse model of viral bronchiolitis
}

\author{
Avraham Beigelman*1, Cassandra L Mikols², Sean P Gunsten², Carolyn L Cannon'1, Steven L Brody² and \\ Michael J Walter ${ }^{2}$
}

\begin{abstract}
Background: Viral bronchiolitis is the leading cause of hospitalization in young infants. It is associated with the development of childhood asthma and contributes to morbidity and mortality in the elderly. Currently no therapies effectively attenuate inflammation during the acute viral infection, or prevent the risk of post-viral asthma. We hypothesized that early treatment of a paramyxoviral bronchiolitis with azithromycin would attenuate acute and chronic airway inflammation.

Methods: Mice were inoculated with parainfluenza type 1, Sendai Virus (SeV), and treated daily with PBS or azithromycin for 7 days post-inoculation. On day 8 and 21 we assessed airway inflammation in lung tissue, and quantified immune cells and inflammatory mediators in bronchoalveolar lavage (BAL).

Results: Compared to treatment with PBS, azithromycin significantly attenuated post-viral weight loss. During the peak of acute inflammation (day 8), azithromycin decreased total leukocyte accumulation in the lung tissue and BAL, with the largest fold-reduction in BAL neutrophils. This decreased inflammation was independent of changes in viral load. Azithromycin significantly attenuated the concentration of BAL inflammatory mediators and enhanced resolution of chronic airway inflammation evident by decreased BAL inflammatory mediators on day 21 .

Conclusions: In this mouse model of paramyxoviral bronchiolitis, azithromycin attenuated acute and chronic airway inflammation. These findings demonstrate anti-inflammatory effects of azithromycin that are not related to anti-viral activity. Our findings support the rationale for future prospective randomized clinical trials that will evaluate the effects of macrolides on acute viral bronchiolitis and their long-term consequences.
\end{abstract}

\section{Background}

Viral bronchiolitis is the most common acute infection of the lower respiratory tract in infancy, and is most often caused by the paramyxoviruses, especially respiratory syncytial virus (RSV). RSV will infect $95 \%$ of children by the age of 2 [1], and up to $3 \%$ of infected children will develop a severe bronchiolitis requiring hospitalization [2]. The rate of admissions has doubled in the past 2 decades [3]; as a result, severe RSV bronchiolitis is now the leading cause of hospitalization in infants younger the age of 1 year [4]. Chronic respiratory symptoms are common after severe RSV bronchiolitis, with about $40 \%$ of hospitalized children eventually developing asthma [5-8]. The development of asthma following RSV infection

* Correspondence: beigelman_a@kids.wustl.edu

${ }^{1}$ Division of Allergy, Immunology \& Pulmonary Medicine, Department of Pediatrics, Washington University School of Medicine, St. Louis, MO; USA Full list of author information is available at the end of the article appears to be related to the severity of the initial infection [9]. RSV infection is not limited to children and contributes significantly to morbidity and mortality in the elderly population [10]. These findings suggest that attenuating the acute viral infection may be an effective strategy to attenuate the acute and long-term consequences of viral bronchiolitis.

No specific therapies are currently recommended for severe RSV bronchiolitis [11]. Ideally a beneficial pharmacologic agent would reduce acute morbidity as well as modify the anti-viral host response to avert the subsequent development of asthma. One class of potentially useful therapeutic agents is the macrolide antibiotics, since they possess distinct anti-inflammatory properties in addition to their antimicrobial effects [12-25]. Two clinical studies have evaluated macrolide treatment during severe RSV bronchiolitis in children, but these studies 
have yielded conflicting results [26,27]. Therefore, definitive conclusions regarding the usefulness of macrolides as a treatment of viral-bronchiolitis cannot be made at this time.

To examine the anti-inflammatory properties of macrolides in a high fidelity animal model of human RSV bronchiolitis, we tested the ability of azithromycin to modulate a well-characterized viral bronchiolitis model using a mouse parainfluenza type I virus, referred to as Sendai virus $(\mathrm{SeV})[28,29]$. SeV replicates at high efficiency in the mouse lung and results in an acute viral bronchiolitis, and chronic airway inflammation that persists for at least one year following viral inoculation $[28,29]$. We hypothesized that treatment of mouse $\mathrm{SeV}$ bronchiolitis with azithromycin during the acute infection would attenuate early airway inflammation, and also decrease the chronic post-viral pathologic abnormalities, such as immune cell accumulation and the mediators that drive these processes.

\section{Materials and methods Mice}

C57BL/6J female mice were purchased from the Jackson Laboratory (Bar Harbor, ME). All mice were bred and housed under specific pathogen-free conditions at Washington University School of Medicine where sentinel mice (pathogen free ICN-strain) exhibited no serologic or histologic evidence of exposure to 15 murine pathogens (including $\mathrm{SeV}$ ). Before performing these in vivo experiments, we investigated whether our colony of mice were actively infected or colonized with bacteria in the trachea and lungs. We obtained tracheal swabs and tissue samples from both lungs, from 5 mice, and plated them on tryptic soy agar plates supplemented with $5 \%$ sheep blood, incubated for 48 hours at $37^{\circ} \mathrm{C}$ and no colonies were identified. To determine if our colony of mice had serologic evidence of prior Mycoplasma pulmonis exposure, serum was collected for indirect ELISA using Mycoplasma pulmonis antigen-coated plates according to manufacturer's recommendations (Charles River Laboratories, Wilmington, MA). These results were negative for infection as previously included in our prior manuscript [30]. In addition, we have tested our SeV stock for bacterial contamination by streaking the viral stock on tryptic soy agar plates supplemented with $5 \%$ sheep blood followed by incubated for 48 hours at $37^{\circ} \mathrm{C}$. No colonies were identified. The Institutional Animal Use and Care Committee of Washington University School of Medicine approved all animal experiments.

\section{Induction of viral bronchiolitis}

$\mathrm{SeV}$, a mouse parainfluenza type 1 virus that is similar to the human paramyxoviruses (a class of viruses that includes RSV, metapneumovirus, and parainfluenza viruses) was used to generate airway inflammation of the small airways (i.e., viral bronchiolitis) as we previously described [29,31,32]. On day zero, seven-week-old C57BL/6J female mice underwent anesthesia and intranasal inoculation with SeV (Fushimi Strain, ATCC \#VR$105)$ at 5,000 egg infectious dose $50 \%(5 \mathrm{~K})$. This dose generates a sub-lethal tracheobronchitis/bronchiolitis viral infection [31,32]. On days 8 and 21 post-inoculation, the mice were anesthetized and euthanized for bronchoalveolar lavage (BAL) fluid and lung tissue collection as we previously described (see experiment design, Figure 1A) [29-33]. The day 8 time point corresponds to the peak of acute airway inflammation, while the day 21 time point corresponds to a chronic inflammatory phase of the infection [29,31]. Each experiment was repeated 3 times with multiple animals in each treatment group.

\section{Azithromycin treatment}

Mice were treated daily with subcutaneous azithromycin $(50 \mathrm{mg} / \mathrm{kg}$ dissolved in $100 \mu \mathrm{L}$ sterile PBS, purchased from Pfizer Pharmaceuticals, Dublin, Ireland), from day 0 (one hour after $\mathrm{SeV}$ inoculation) through day 7 post-viral inoculation. Mice that were treated with subcutaneous $100 \mu \mathrm{L}$ sterile PBS served as a control for the azithromycin treatment. Azithromycin dose was determined based on our previous pharmacokinetic studies [30] which demonstrated that daily subcutaneous treatment of mice with azithromycin $(50 \mathrm{mg} / \mathrm{kg})$ produced serum levels similar to those observed in humans treated with the recommended azithromycin dose. Overall, a higher dosage of azithromycin is required in mice than humans due to more rapid liver metabolism in mice, resulting in an elimination half-life of 2.3 hours compared to 68 hours in humans $[34,35]$.

\section{Mouse specimen analyses}

BAL and lung tissue harvest were performed as previously described [29-32]. Two blinded observers determined the BAL immune cell differential using standard light microscopy criteria as described previously [30,31]. BAL inflammatory mediators were analyzed using a multiplex flow-cytometry based assay according to manufacturer's recommendations (Bio-Rad Laboratories) and as previously described [30,31]. The detection limit for the Bio-plex mouse cytokine 23-plex panel (Bio-Rad) is: IL$1 \alpha-2 \mathrm{pg} / \mathrm{ml}$; IL-1 $\beta$ - 2 pg/ml; IL-2 - 3 pg/ml; IL-3 - 2 pg/ $\mathrm{ml}$; IL-4 - 3 pg/ml; IL-5 - $2 \mathrm{pg} / \mathrm{ml}$; IL-6 - 2 pg/ml; IL-9 - 15 $\mathrm{pg} / \mathrm{ml}$; IL-10 - 2 pg/ml; IL-12 (p40) - 2 pg/ml; IL-12 (p70) - $4 \mathrm{pg} / \mathrm{ml} ; \mathrm{IL}-13$ - $9 \mathrm{pg} / \mathrm{ml}$; IL-17 - $1 \mathrm{pg} / \mathrm{ml}$; eotaxin - 148 $\mathrm{pg} / \mathrm{ml}$; G-CSF - $1 \mathrm{pg} / \mathrm{ml}$; GM-CSF - 7 pg/ml; IFN- $\gamma-6 \mathrm{pg} /$ $\mathrm{ml}$; KC - 3 pg/ml; CCL2/JE - 14 pg/ml; CCL3/MIP- $1 \beta-24$ $\mathrm{pg} / \mathrm{ml}$; CCL4/MIP-1i - 2 pg/ml; CCL5/RANTES - 5 pg/ $\mathrm{ml}$; and TNF- $\alpha-6 \mathrm{pg} / \mathrm{ml}$. 
A

SeV Infection

Day:

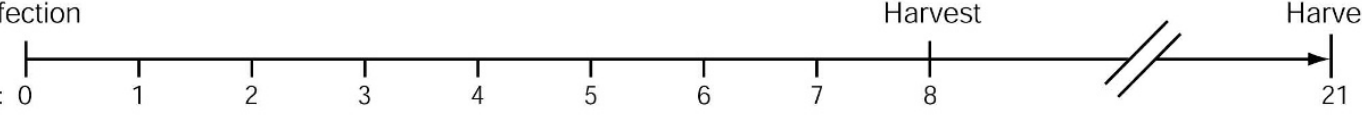

Azithro / PBS

B

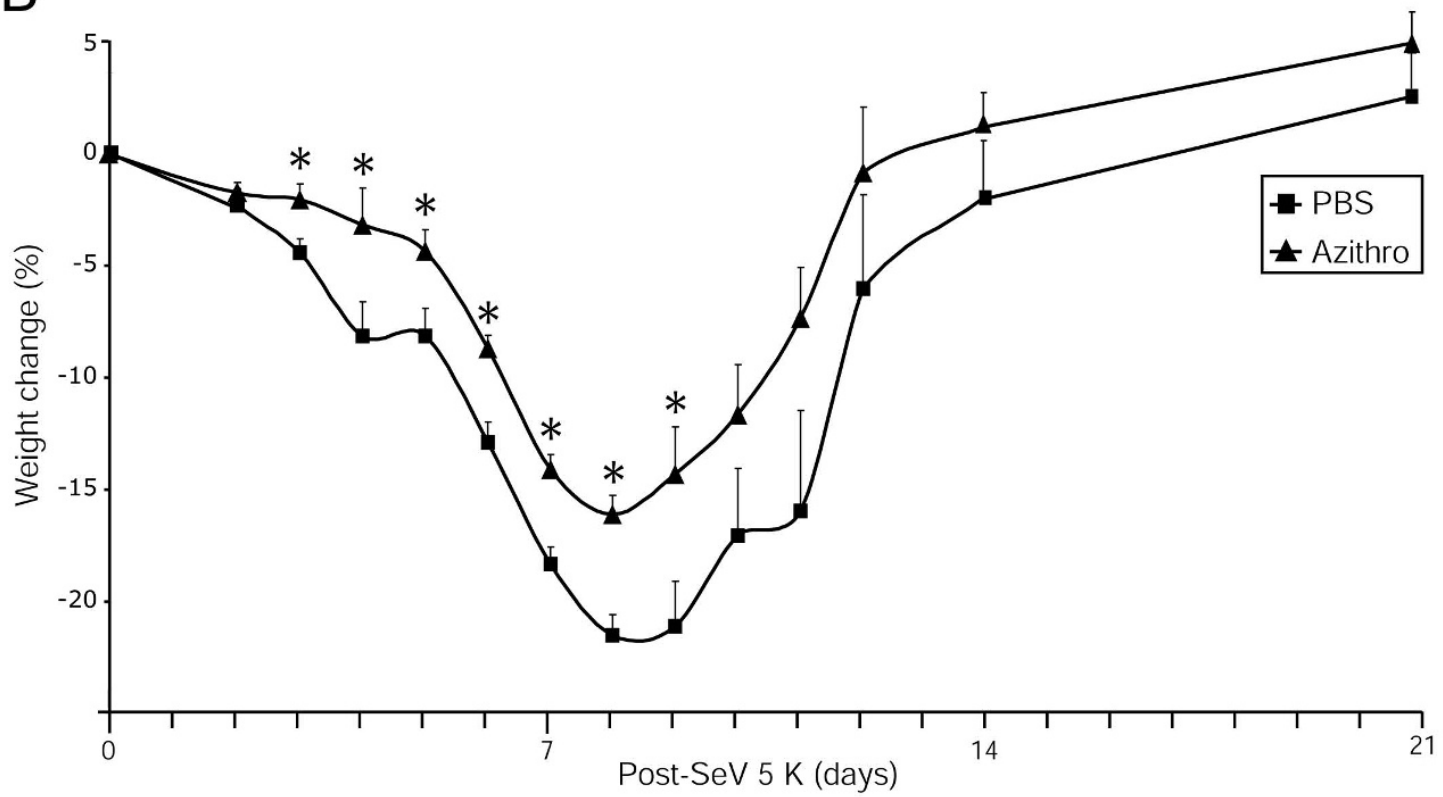

C

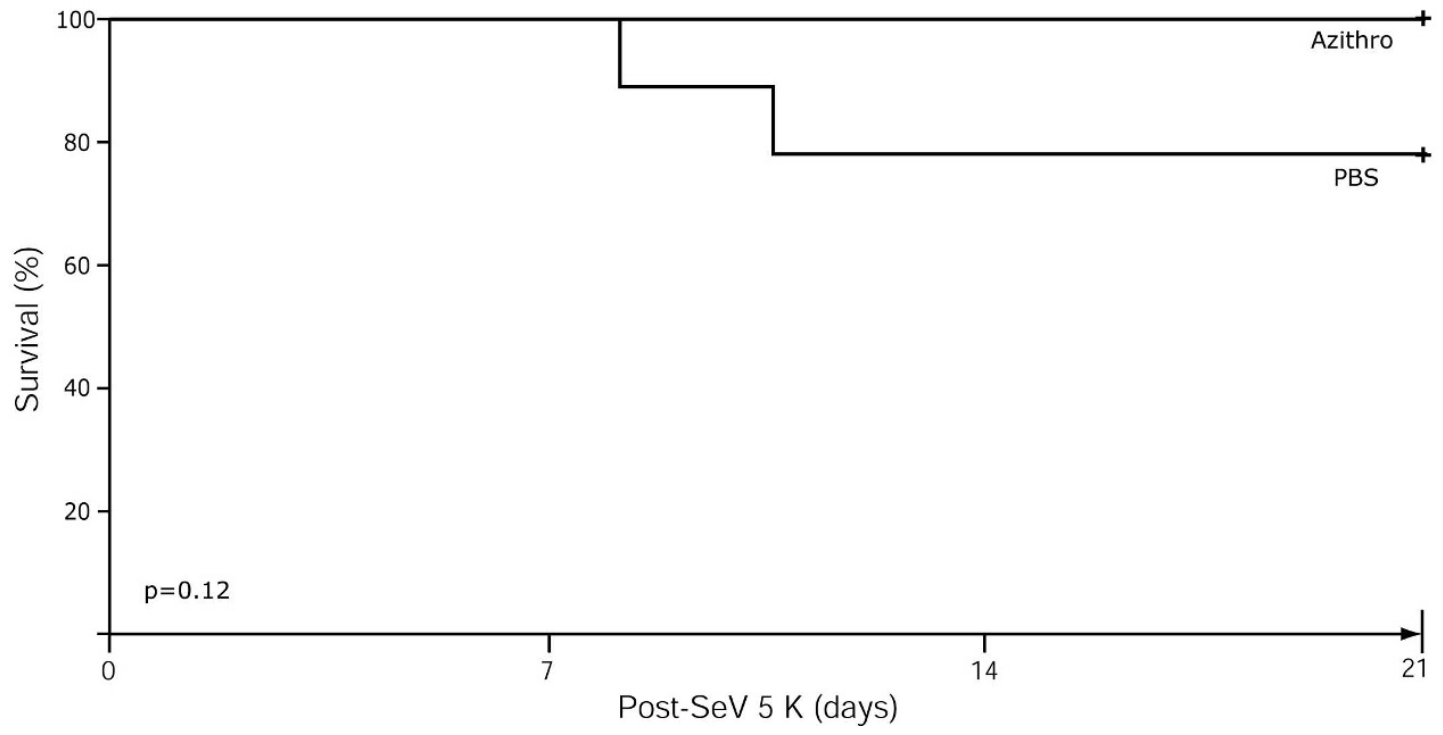

Figure 1 Azithromycin attenuated viral-dependent weight loss. (A) Experiment time line. Seven-week-old C57BL/6J female mice were inoculated with Sendai virus 5,000 egg infectious dose $50 \%$ (SeV 5 K). Mice were treated daily with PBS or azithromycin day 0 (one hour after SeV inoculation) through day 7. On days 8 and 21, bronchoalveolar lavage (BAL) fluid and lungs and were harvested. (B) Percentage of weight change from baseline (day 0 ) in PBS (black square) versus azithromycin (black triangle) treated mice. Values are the mean \pm SEM $(n=23$ in each group). A significant decrease between PBS and azithromycin treatment is indicated $\left({ }^{*}, p<0.05\right)$. (C) Kaplan-Meier analysis of survival. No statistical difference between treatment groups ( $n=23$ in each group) was determined by log-rank test. 
Lung sections were stained with hematoxylin and eosin (H\&E) and Periodic Acid-Schiff (PAS) [30,31]. Quantification of mucus producing cells was performed by counting the number of airway cells that stained with PAS positive cells and using a PAS score as previously described [30,36,37]. Peripheral blood leukocyte counts were performed using an automated veterinary hematologic analyzer with a pre-programmed murine calibration mode (Hemavet 950FS, Drew Scientific, Waterbury, CT) as previously described [31].

\section{PCR Quantification of Sendai virus}

The quantity of Sendai virus-specific RNA was determined from whole lung using a TaqMan one-step fluorogenic RT-PCR reaction according to the manufacturer's recommendation (Applied Biosystems, Foster City, CA) $[29,31]$. Lung tissue was placed in RNA Later (Applied Biosystems), homogenized with stainless steel beads for 3 min (Biospect Products Inc., Bartlesville, OK), and column purified with an RNeasy mini kit according to the manufacturer's recommendations (Qiagen, Alencia, CA). Duplicate serial 10-fold dilutions of total RNA from Sendai-infected lung tissue underwent one-step fluorogenic RT-PCR for detection of Sendai virus nucleocapsid protein transcripts (upstream primer 5'-TCCACCCTGAGGAGCAGG-3'; downstream primer 5'-ACCCGGCCAT CGTGAACT-3'; probe 5'-6FAM-TGGCAGCAAAGCAA AGGGTCTGGA-TAMRA-30) and murine GAPDH specific RNA (proprietary primer/probe combination, Applied Biosystems; \#MM99999915G1) to construct standard curves. Sendai values were calculated as the mean of duplicate samples from reactions with a cycle threshold between 20 and 25 and final results were normalized to GAPDH and reported as the Sendai/GAPDH ratio.

\section{Statistical analysis}

Means from multiple groups (BAL cell counts and inflammatory mediator concentrations on day 8) were analyzed for statistical significance using a one-way analysis of variance (ANOVA) and post hoc comparison to identify significant differences between specific groups. An independent group's t-test was used to compare means from two groups (BAL cell counts and inflammatory mediator concentrations on day 21). The MannWhitney test was used to compare the lung PAS scores (an ordinal variable). The significance level for all tests was 0.05 . Data were analyzed using SPSS 15 software (Chicago, IL).

\section{Results}

\section{Azithromycin attenuated viral-dependent weight loss}

To determine if azithromycin could confer anti-inflammatory properties in a mouse model of viral bronchioli- tis, we inoculated mice on day 0 with $\mathrm{SeV}(5,000$ egg infectious dose $50 \%, 5 \mathrm{~K}$ ) and treated the mice daily with azithromycin or PBS from day 0 to day 7 (Figure 1A). Mice treated with azithromycin had attenuated weight loss compared to PBS treated mice, with significant differences observed on days 3 through 9 post-inoculation (Figure 1B). We noted a trend toward lower mortality in the azithromycin treated mice (Figure 1C): 23/23 mice survived in the azithromycin group versus $21 / 23$ in the control group ( $\mathrm{p}=0.12$ ). To assess whether azithromycin treatment would be beneficial using a higher infectious dose, we performed an experiment using a lethal infectious dose of virus (50,000 egg infectious dose 50\%, $50 \mathrm{~K}$ ). Treatment of this lethal infection with azithromycin did not significantly alter weight loss, overall survival or delay the time of death compared to treatment with PBS $(\mathrm{N}=5$ in each cohort). These results demonstrated that azithromycin treatment, in the $5 \mathrm{~K}$ infectious dose, attenuated some clinical features of the severity of the acute viral bronchiolitis. Therefore, we next sought to characterize the impact of azithromycin treatment on lung inflammation.

\section{Azithromycin attenuated viral-dependent airway inflammation}

To determine whether azithromycin treatment could attenuate airway inflammation during the SeV $5 \mathrm{~K}$ infection, we examined the lungs from PBS and azithromycin treated mice 8 days following viral inoculation. This time point correlates to peak post-viral airway inflammation [31]. Compared to naive mice, $\mathrm{SeV}$ inoculated mice treated with PBS had an accumulation of immune cells predominantly in the peribronchial space, in the airway lumen, and to a lesser extent in the alveolar spaces. In some airways we observed severe epithelial cell injury with disruption of the epithelial layer as described previously (Figure 2, middle panels) [38]. Treatment with azithromycin attenuated the accumulation of inflammatory cells in the lung tissue (Figure 2, right panels). To quantify the accumulation of immune cells in the airways we collected the BAL fluid. In agreement with the histologic appearance of the lung tissue, azithromycin treatment significantly attenuated the accumulation of total BAL immune cells (Figure 3A). Analysis of the BAL leukocyte populations demonstrated that azithromycin treatment significantly decreased the accumulation of macrophages, lymphocytes and neutrophils, with the largest fold-reduction in the number of neutrophils (Figure 3B-D). To exclude the possibility that azithromycin treatment decreased accumulation of immune cells in the airways by a systemic depletion of immune cells, we quantified total and differential leukocytes in the peripheral blood at day 8 post-viral inoculation. We observed no significant differences between PBS and azithromycin- 


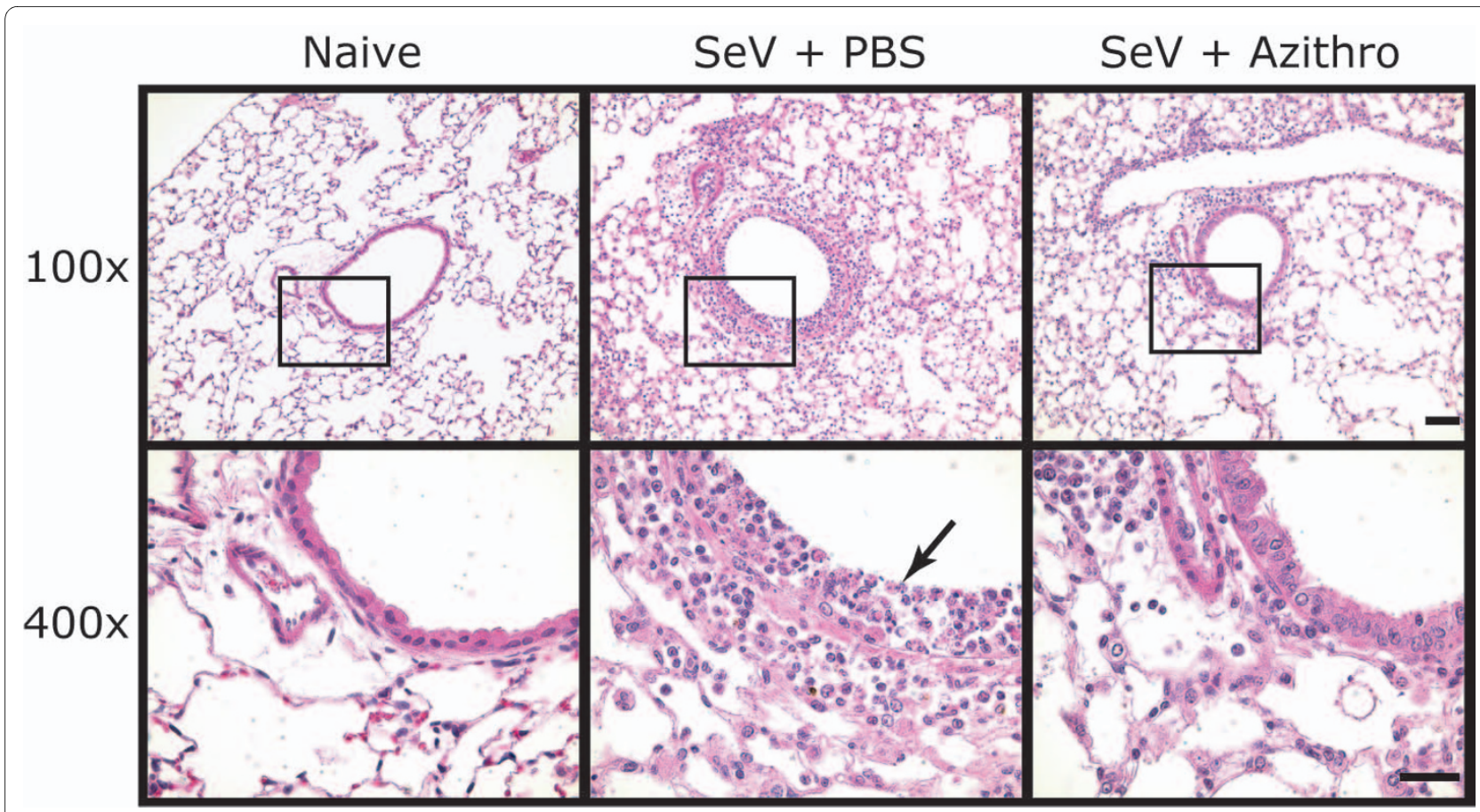

Figure 2 Azithromycin attenuated viral-dependent airway inflammation. Mice were inoculated with SeV and treated as in Figure 1. Eight days post-viral inoculation, lung sections were obtained from naive mice (Naive, left column); SeV infected mice treated with PBS (SeV + PBS, middle column), and SeV infected mice treated with azithromycin (SeV + Azithro, right column). Representative photomicrographs of hematoxylin and eosin stained lung sections are shown ( $n=11$, Azithro; $n=12$, PBS). Inflammatory cells within the airway are indicated (arrow). Bar $=50 \mu m$ (top) and $25 \mu m$ (bottom).

treated cohorts, in terms of total leukocytes (mean cells/ $\mu \mathrm{L} \pm \mathrm{SD}, 4100 \pm 1300$ vs. $4000 \pm 600$ respectively; $\mathrm{p}=$ 0.81 ) or numbers of macrophages, lymphocytes or neutrophils (data not shown). Thus, azithromycin treatment attenuated lung inflammation in this model of viral bronchiolitis.

\section{Azithromycin attenuated viral-dependent airway inflammation is associated with decreased concentrations of BAL inflammatory mediators}

Based on the observation that azithromycin treatment decreased immune cell accumulation on day 8 post-inoculation, we proposed that azithromycin treatment would also be associated with decreased concentration of BAL inflammatory mediators. Compared to $\mathrm{SeV}$ inoculated mice treated with $\mathrm{PBS}$, treatment with azithromycin attenuated the expression of multiple BAL chemokines and growth factors (Figure 4A-D, column 2 versus 3). Importantly, we observed a significant azithromycindependent decrease in G-CSF and decreased concentrations, albeit not statistically significant, of CCL2/JE, CCL3/MIP- $1 \alpha$, CCL4/MIP- $1 \beta$ and CCL5/RANTES; all these are proteins known to mediate viral immune response (e.g., chemotaxis and activation of inflammatory cells at site of inflammation). In addition, azithromycin treatment resulted in trends toward lower concentrations of multiple other inflammatory mediators in the BAL (IL-1 $\beta$, IL-5, IL-6, IL-9, IL-10, IL-12, GM-CSF and IFN- $\gamma$ ), but had no effect on concentration of IL-17 and CXCL1/KC (data not shown). These data demonstrate that azithromycin moderated the viral-dependent secretion of multiple BAL mediators, several of which are critical for chemotaxis and activation of inflammatory cells.

\section{Azithromycin modulation of viral-dependent airway inflammation is independent of Sendai viral load} To investigate whether azithromycin had an effect on $\mathrm{SeV}$ burden in the lung tissue, we quantified SeV-specific RNA at day 5 and 8 post-viral inoculation. These time points were chosen based on our previous data that demonstrated peak viral load in the lungs occurred on day 5 post-inoculation, and virus clearance on day 8 post-inoculation [31]. There were no differences in $\mathrm{SeV}$-specific RNA between PBS or azithromycin treated mice suggesting azithromycin does not directly alter viral replication or clearance (Figure 5). Thus, in this model of viral bronchiolitis, azithromycin anti-inflammatory properties are independent of an anti-viral property.

\section{Azithromycin treatment attenuated chronic viral- dependent airway inflammation}

As noted above, azithromycin treatment from day 0 through day 7 post-viral inoculation attenuated viral- 


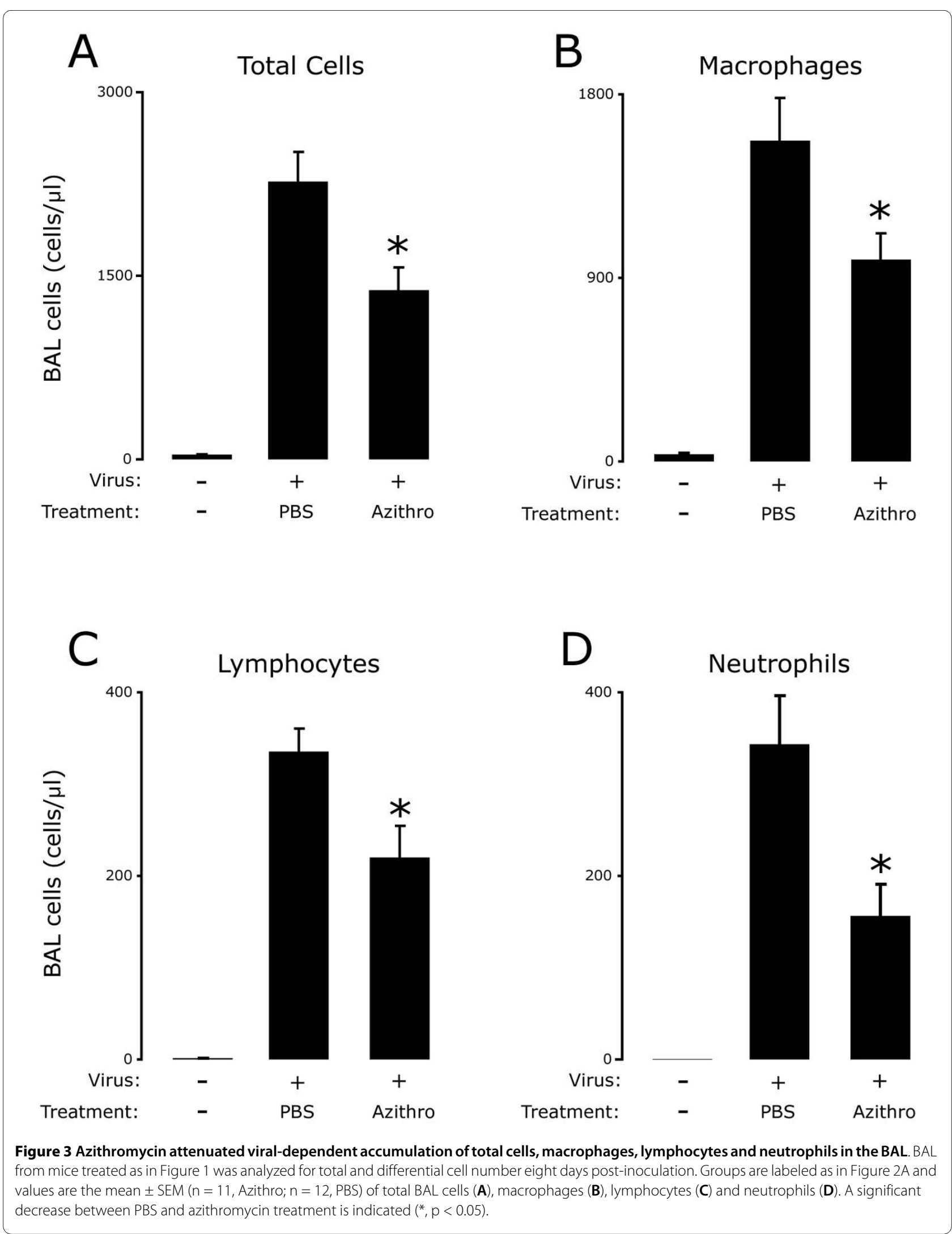




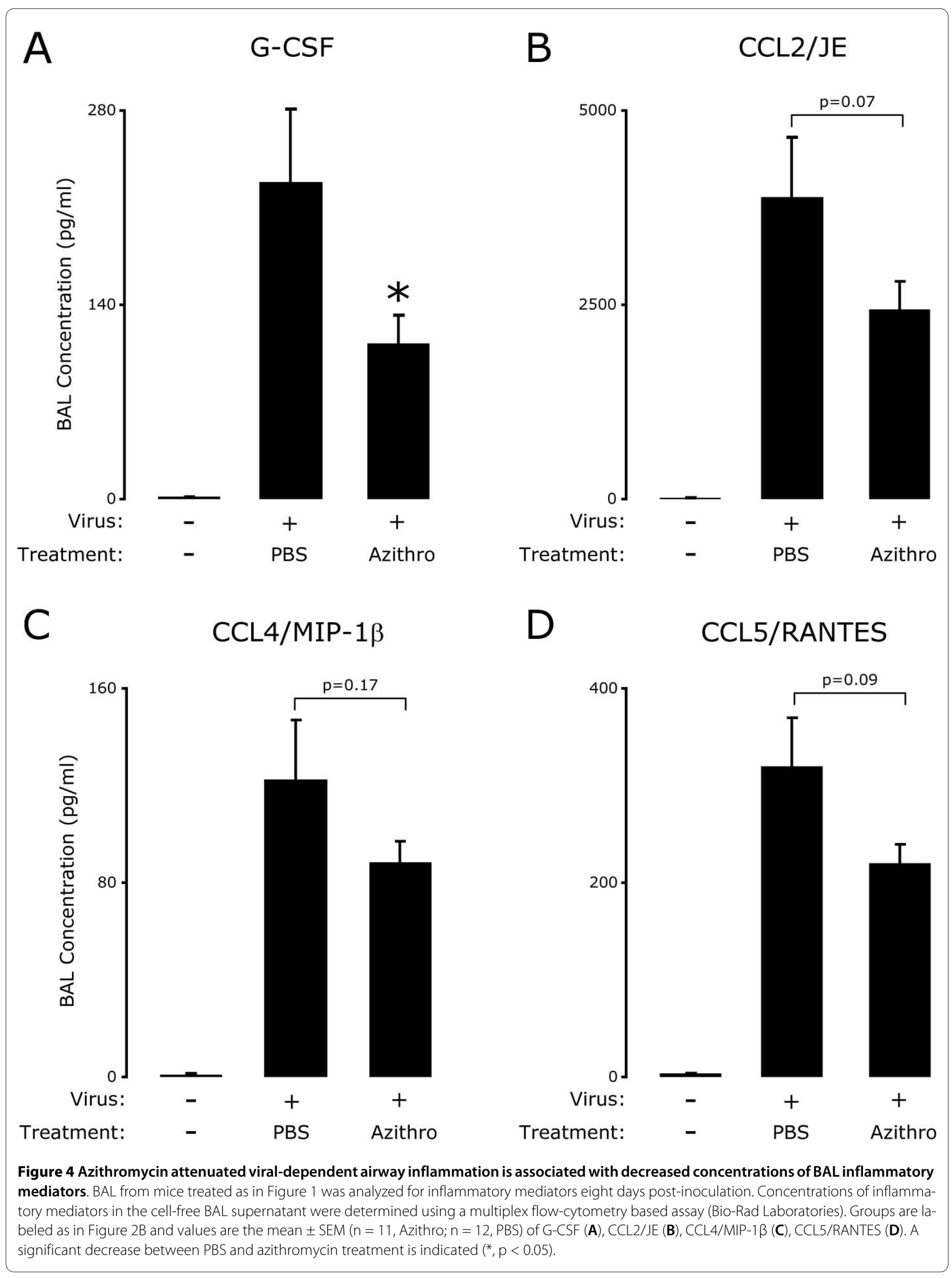



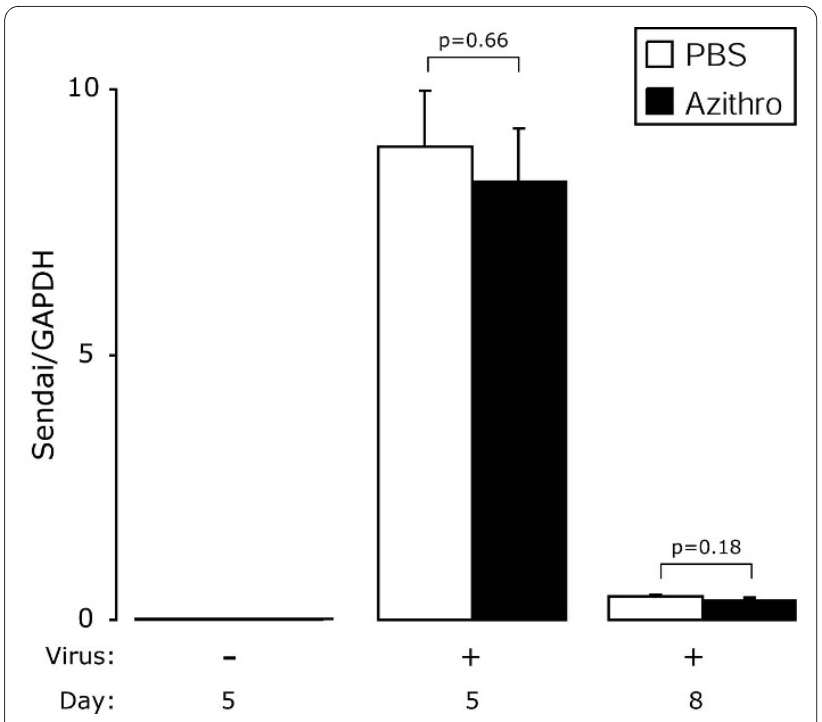

Figure 5 Azithromycin attenuated viral-dependent airway inflammation is independent of Sendai virus load. Mice were inoculated with $\mathrm{SeV}$ and treated as in Figure 1. Five and eight days postinoculation, whole-lung RNA was analyzed for Sendai virus-specific and GAPDH RNA by one-step fluorogenic reverse transcriptase-polymerase chain reaction (RT-PCR). The mean of duplicate measurements of SeV-specific RNA was normalized to GAPDH and reported as the SeV to GAPDH ratio. Values are the mean $\pm \operatorname{SEM}(n=6$, day $5 ; n=4$, day 8$)$.

dependent airway inflammation at day 8 (peak of inflammation). Next we investigated whether azithromycin would also modify the chronic inflammatory phase of the infection. On day 21 post-viral inoculation, the accumulation of total BAL immune cells was elevated compared to naive mice. There were fewer total cells (although not statistically significant) in the BAL of the azithromycin treated cohort compared to those treated with PBS (Figure 6A). There was a trend toward fewer BAL neutrophils in the azithromycin treated mice (Figure 6B). Moreover, azithromycin treatment resulted in a significant decrease in the BAL concentrations of G-CSF and CXCL1/KC (Figure 6C-D), and in a trend toward a decreased concentration of CCL2/JE (data not shown). No statistical difference was noted between the azithromycin and PBS treated mice in terms of the extent of mucous cell metaplasia (PAS score 1.1 vs. 1.0 respectively; $\mathrm{p}=0.58$ ). These results demonstrated that azithromycin treatment altered not only acute airway inflammation, but modified certain key aspects of the chronic inflammatory phase of the infection.

\section{Discussion}

This study demonstrated that azithromycin possessed beneficial anti-inflammatory properties in a mouse model of paramyxoviral bronchiolitis. Azithromycin treatment improved the course of acute disease, evidenced by decreased weight loss and attenuated accumu- lation of BAL inflammatory cells and chemokines. Although not statistically significant, we noted a trend toward lower mortality in the azithromycin treated mice. We also observed that early azithromycin treatment was associated with modulation of certain features of the chronic post-viral inflammatory phase. To the best of our knowledge, this is the first study to demonstrate the beneficial effects of azithromycin in a mouse model of viral bronchiolitis and suggests this drug may also have beneficial effects in human bronchiolitis.

Our results are in agreement with a previous study by Sato and colleagues, who investigated the effect of erythromycin treatment using an in vivo model of influenza pneumonia [39]. That study showed that erythromycin treatment in mice resulted in improved survival, decreased weight loss, and attenuated airway inflammation. Our results extend those findings by demonstrating that a clinically better tolerated macrolide displayed antiinflammatory properties in a different viral infection model (i.e., a parainfluenza viral bronchiolitis vs. influenza pneumonia). In addition, we demonstrated that treatment of the acute inflammation is associated with attenuation of the chronic post-viral inflammatory phase.

Our results revealed that azithromycin had no effect on $\mathrm{SeV}$ viral kinetics in the lung tissue at day 5 and 8 postviral inoculation, time points that corresponded to the peak of viral load in the lungs and virus clearance respectively [31]. Accordingly, in this case we conclude that azithromycin has anti-inflammatory, but no direct in vivo anti-viral properties. This observation agrees with the previously mentioned report, in which erythromycin treatment did not alter influenza viral kinetics [39]. Although weight loss is attenuated and viral clearance is not compromised by treatment with azithromycin, it remains unclear how azithromycin or other macrolides would alter additional clinical outcomes of a human viral infection such as nasal congestion, nasal discharge, and cough as we have not developed techniques to quantitate these in the mouse. We do note that a recent study found that macrolide antibiotics inhibited RSV infection in isolated human tracheal epithelial cells [40]. These apparently conflicting results could be related to differences between in vivo and in vitro viral infection models, use of different paramyxoviruses, or to different dosing regimens and pharmacologic properties of the drugs.

During the peak inflammatory response, azithromycin treatment attenuated cellular influx in the lung tissue and BAL. Decreased cellular influx in site of inflammation is consistent with previous reports in other inflammatory models in which macrolides attenuated neutrophilic inflammation induced by inhaled LPS [41,42] or intratracheal $P$. aeruginosa infection [43]. The effect of azithromycin, in our viral bronchiolitis model, does not appear to be neutrophil-specific since the accumulation of mac- 


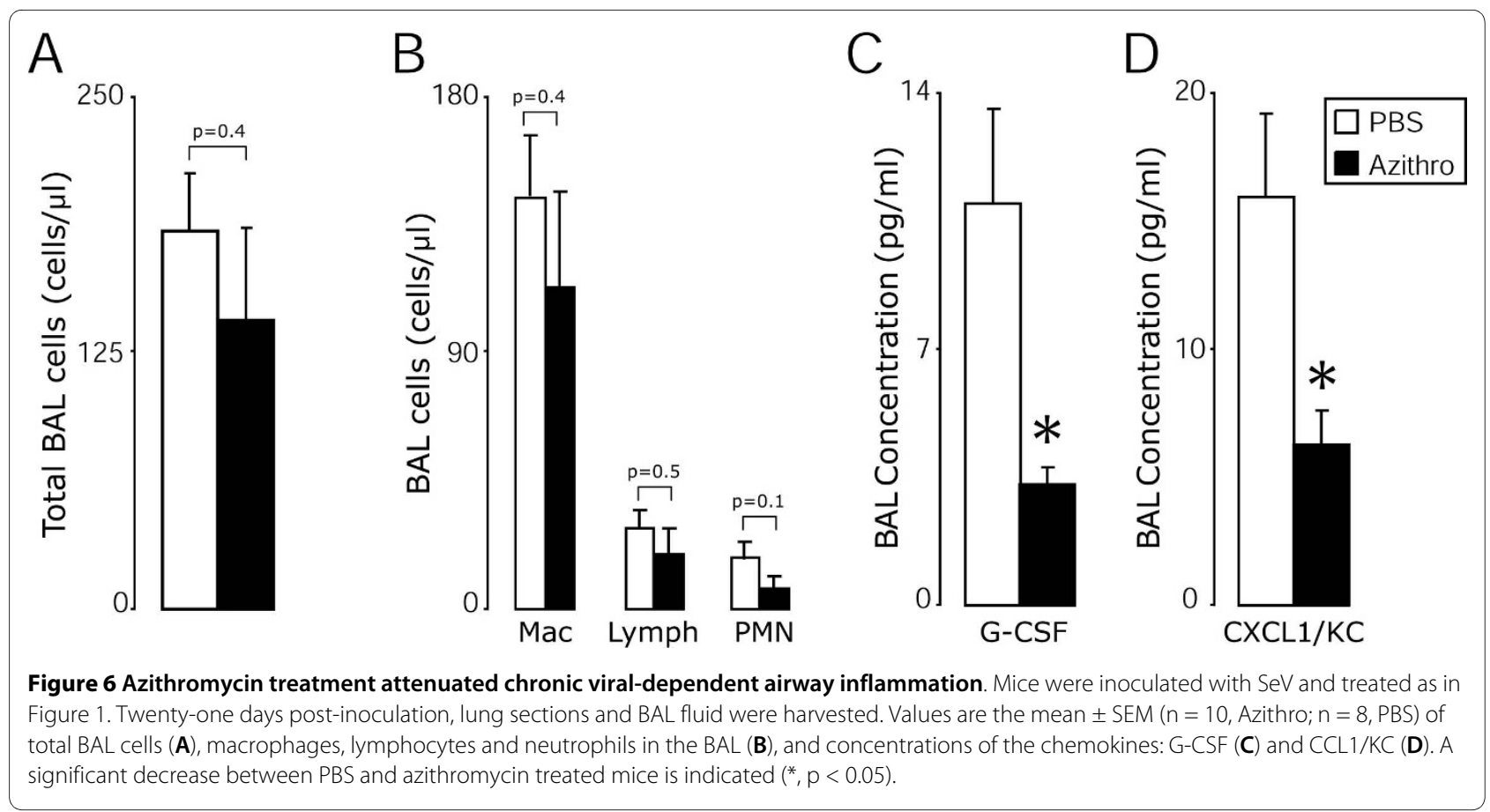

rophages and lymphocytes were also attenuated. In previous work, we demonstrated that azithromycin had the most profound effect on eosinophils in an in vivo allergic model of airway inflammation [30]. Taken together, these observations suggest that macrolides possess broad antiinflammatory properties that can attenuate the accumulation of multiple cell types in various airway inflammatory models.

One limitation of this study is the initiation of azithromycin treatment on the day of infection. Another limitation is that we did not test for a beneficial treatment effect of azithromycin on other respiratory viruses, such as RSV. RSV is a human pathogen and in our experience RSV infection of mice results in pneumonia rather then bronchiolitis. We have found that $\mathrm{SeV}$ replicates at high efficiency in the mouse lung and results in acute inflammation of the small airways (i.e., bronchiolitis) that better mimics human bronchiolitis. Since we have not tested for a beneficial treatment effect of azithromycin on RSV infection it is difficult to compare our results to previous studies that modulated the host immune response by blocking the CX3C chemokine activity of the G protein of RSV [44-46]. Future studies will be required to determine if different treatment regimens, such as initiation of treatment a few days after inoculation or alternate dosing regimens would result in a similar beneficial treatment effect on $\mathrm{SeV}$ as well as other respiratory viruses.

Although the precise biochemical mechanisms responsible for the anti-inflammatory effects of macrolides are not defined, this family of drugs can inhibit multiple cellular processes involved in an inflammatory response. For example, macrolides have been shown to inhibit neutrophil chemotaxis, leukocyte-epithelial cell adhesion, cytokine secretion and cytokine-dependent intracellular signaling $[43,47]$. In this regard, macrolides block NF- $к B$ and AP-1 dependent gene transcription of inflammatory mediators $[42,48,49]$. Thus, additional studies will be required to further define the precise cellular mechanisms responsible for the anti-inflammatory effects of azithromycin and to determine the optimal dosing regimens required to attenuate both the acute and chronic post-viral inflammatory phenotypes.

Previous clinical studies have shown that macrolides are beneficial in the treatment of inflammatory airway diseases such as diffuse panbronchiolitis [13], cystic fibrosis [14], and asthma [15-25]. Two previous studies investigated the effects of macrolide treatment in children hospitalized with RSV bronchiolitis [26,27]. Tahan et al. [27] revealed that a 21 day course of clarithromycin treatment reduced length of hospital stay, the duration of additional treatments (supplemental oxygen, intravenous fluids and bronchodilators) and the day 21 concentrations of IL-4, IL-8 and eotaxin in the serum. However, this study was limited by a relatively small sample size (n $=21$ ). In a recent larger study, Kneyber et al. found that azithromycin treatment did not improve the early disease course in infants hospitalized with RSV bronchiolitis [26]. This study, although important, had two main limitations that may have obscured any potential benefits of the macrolide. First, the researchers designed an equivalence study based on the assumption that a difference less than \pm 49.4 hours (approximately \pm 2 days) in length of 
hospitalization would be considered as equivalence (i.e., no benefit for treatment). Therefore, this study was not powered to detect smaller differences in length of hospitalization. Second, the researchers recruited only $71 \%$ of the required study population that was determined based on their power analysis. This early termination of the trial prevents definitive conclusions.

The current study highlights the importance of measuring macrolide-dependent effects during the early phase of the viral infection as well as the late phase. In addition we have identified certain growth factors and chemokines (i.e., G-CSF, CCL2, CCL4, CCL5, and CXCL1) that could be tracked to establish a beneficial treatment effect. Accordingly, when planning a human study we feel early and long-term follow-up of clinical and biochemical endpoints should be included in the study design.

Our study revealed that treatment of mouse $\mathrm{SeV}$ bronchiolitis with azithromycin during the acute infection would attenuate acute and chronic airway inflammation, and also decrease the chronic post-viral pathologic abnormalities. However, we do not recommend the offlabel use of azithromycin during RSV infection until additional prospective randomized clinical trials support its use since excessive use of macrolides has correlated with increased prevalence of macrolide-resistant organisms such as Streptococcus pneumonia [50].

\section{Conclusions}

Our results extend previous findings obtained in different in vivo models by demonstrating that azithromycin possessed anti-inflammatory properties in an in vivo model of viral bronchiolitis. We found that early treatment during viral infection is associated with attenuation of acute and chronic airway inflammation. Azithromycin treatment improved the course of acute disease, evidenced by decreased weight loss and attenuated accumulation of BAL inflammatory cells and chemokines. Our data revealed that early azithromycin treatment also modulates the chronic post-viral inflammatory phase. These results support the rationale for future prospective randomized clinical trials that will evaluate the effects of macrolides on acute viral bronchiolitis and their longterm consequences.

\section{Abbreviation list}

ANOVA: Analysis of Variance; BAL: Bronchoalveolar Lavage; GAPDH: Glyceraldehyde 3-Phosphate Dehydrogenase; H\&E: Hematoxylin and Eosin; PAS: Periodic Acid-Schiff; RSV: Respiratory Syncytial Virus; SeV: Sendai Virus.

\section{Competing interests disclosures}

The authors declare that they have no competing interests.

\section{Authors' contributions}

$A B$ : Designed the study, performed the experiments, performed statistical analysis, interpreted the data, and wrote the manuscript. CLM, SG: Performed the experiments, participated in revision of the manuscript, provided final approval of the manuscript. CLC, SLB: Participated in study design, participated in revision of the manuscript, provided final approval of the manuscript. MJW: Designed the study, performed statistical analysis, interpreted the data, and wrote the manuscript. All authors read and approved the final manuscript.

\section{Acknowledgements}

This work was supported by the National Institutes of Health [NIH R01HL083894].

\section{Author Details}

'Division of Allergy, Immunology \& Pulmonary Medicine, Department of Pediatrics, Washington University School of Medicine, St. Louis, MO; USA and 2Division of Pulmonary and Critical Care Medicine, Department of Internal Medicine, Washington University School of Medicine, St. Louis, MO; USA

Received: 2 March 2010 Accepted: 30 June 2010

Published: 30 June 2010

\section{References}

1. Glezen WP, Taber LH, Frank AL, Kasel JA: Risk of primary infection and reinfection with respiratory syncytial virus. Am J Dis Child 1986, 140(6):543-546.

2. Boyce TG, Mellen BG, Mitchel EF Jr, Wright PF, Griffin MR: Rates of hospitalization for respiratory syncytial virus infection among children in medicaid. J Pediatr 2000, 137(6):865-870.

3. Shay DK, Holman RC, Newman RD, Liu LL, Stout JW, Anderson LJ: Bronchiolitis-associated hospitalizations among US children, 19801996. JAMA 1999, 282(15):1440-1446.

4. Leader S, Kohlhase K: Respiratory syncytial virus-coded pediatric hospitalizations, 1997 to 1999. Pediatr Infect Dis J 2002, 21(7):629-632.

5. Sigurs N: Epidemiologic and clinical evidence of a respiratory syncytial virus-reactive airway disease link. Am J Respir Crit Care Med 2001, 163(3 Pt 2):S2-6.

6. Sigurs N, Bjarnason R, Sigurbergsson F, Kjellman B: Respiratory syncytial virus bronchiolitis in infancy is an important risk factor for asthma and allergy at age 7. Am J Respir Crit Care Med 2000, 161(5):1501-1507.

7. Sigurs N, Gustafsson PM, Bjarnason R, Lundberg F, Schmidt S, Sigurbergsson F, Kjellman B: Severe respiratory syncytial virus bronchiolitis in infancy and asthma and allergy at age 13. Am J Respir Crit Care Med 2005, 171(2):137-141.

8. Castro M, Schweiger T, Yin-Declue H, Ramkumar TP, Christie C, Zheng J, Cohen R, Schechtman KB, Strunk R, Bacharier LB: Cytokine response after severe respiratory syncytial virus bronchiolitis in early life. J Allergy Clin Immunol 2008, 122(4):726-733.

9. Carroll KN, Wu P, Gebretsadik T, Griffin MR, Dupont WD, Mitchel EF, Hartert TV: The severity-dependent relationship of infant bronchiolitis on the risk and morbidity of early childhood asthma. J Allergy Clin Immunol 2009, 123(5):1055-1061.

10. Glezen WP, Greenberg SB, Atmar RL, Piedra PA, Couch RB: Impact of respiratory virus infections on persons with chronic underlying conditions. JAMA 2000, 283(4):499-505.

11. Diagnosis and management of bronchiolitis. Pediatrics 2006, 118(4):1774-1793.

12. Shinkai $M$, Rubin BK: Macrolides and airway inflammation in children. Paediatr Respir Rev 2005, 6(3):227-235.

13. Koyama H, Geddes DM: Erythromycin and diffuse panbronchiolitis. Thorax 1997, 52(10):915-918.

14. Equi A, Balfour-Lynn IM, Bush A, Rosenthal M: Long term azithromycin in children with cystic fibrosis: a randomised, placebo-controlled crossover trial. Lancet 2002, 360(9338):978-984. 
15. Miyatake H, Taki F, Taniguchi H, Suzuki R, Takagi K, Satake T: Erythromycin reduces the severity of bronchial hyperresponsiveness in asthma. Chest 1991, 99(3):670-673.

16. Shimizu T, Kato M, Mochizuki H, Tokuyama K, Morikawa A, Kuroume T: Roxithromycin reduces the degree of bronchial hyperresponsiveness in children with asthma. Chest 1994, 106(2):458-461.

17. Kamoi H, Kurihara N, Fujiwara H, Hirata K, Takeda T: The macrolide antibacterial roxithromycin reduces bronchial hyperresponsiveness and superoxide anion production by polymorphonuclear leukocytes in patients with asthma. JAsthma 1995, 32(3):191-197.

18. Shimizu T, Kato M, Mochizuki H, Takei K, Maeda S, Tokuyama K, Morikawa A: Roxithromycin attenuates acid-induced cough and water-induced bronchoconstriction in children with asthma. JAsthma 1997, 34(3):211-217

19. Amayasu H, Yoshida S, Ebana S, Yamamoto Y, Nishikawa T, Shoji T, Nakagawa H, Hasegawa H, Nakabayashi M, Ishizaki Y: Clarithromycin suppresses bronchial hyperresponsiveness associated with eosinophilic inflammation in patients with asthma. Ann Allergy Asthma Immunol 2000, 84(6):594-598.

20. Black PN, Blasi F, Jenkins CR, Scicchitano R, Mills GD, Rubinfeld AR, Ruffin RE, Mullins PR, Dangain J, Cooper BC, David DB, Allegra L: Trial of roxithromycin in subjects with asthma and serological evidence of infection with Chlamydia pneumoniae. Am J Respir Crit Care Med 2001, 164(4):536-541.

21. Ekici A, Ekici M, Erdemoglu AK: Effect of azithromycin on the severity of bronchial hyperresponsiveness in patients with mild asthma. J Asthma 2002, 39(2):181-185.

22. Kraft M, Cassell GH, Pak J, Martin RJ: Mycoplasma pneumoniae and Chlamydia pneumoniae in asthma: effect of clarithromycin. Chest 2002, 121(6):1782-1788.

23. Kostadima E, Tsiodras S, Alexopoulos El, Kaditis AG, Mavrou I, Georgatou N, Papamichalopoulos A: Clarithromycin reduces the severity of bronchial hyperresponsiveness in patients with asthma. Eur Respir J 2004, 23(5):714-717.

24. Johnston SL, Blasi F, Black PN, Martin RJ, Farrell DJ, Nieman RB: The effect of telithromycin in acute exacerbations of asthma. N Engl J Med 2006, 354(15):1589-1600.

25. Piacentini GL, Peroni DG, Bodini A, Pigozzi R, Costella S, Loiacono A, Boner AL: Azithromycin reduces bronchial hyperresponsiveness and neutrophilic airway inflammation in asthmatic children: a preliminary report. Allergy Asthma Proc 2007, 28(2):194-198.

26. Kneyber MC, van Woensel JB, Uijtendaal E, Uiterwaal CS, Kimpen JL: Azithromycin does not improve disease course in hospitalized infants with respiratory syncytial virus (RSV) lower respiratory tract disease: a randomized equivalence trial. Pediatr Pulmonol 2008, 43(2):142-149.

27. Tahan F, Ozcan A, Koc N: Clarithromycin in the treatment of RSV bronchiolitis: a double-blind, randomised, placebo-controlled trial. Eur Respir J 2007, 29(1):91-97.

28. Kim EY, Battaile JT, Patel AC, You Y, Agapov E, Grayson MH, Benoit LA, Byers DE, Alevy Y, Tucker J, Swanson S, Tidwell R, Tyner JW, Morton JD, Castro M, Polineni D, Patterson GA, Schwendener RA, Allard JD, Peltz G, Holtzman MJ: Persistent activation of an innate immune response translates respiratory viral infection into chronic lung disease. Nat Med 2008, 14(6):633-640.

29. Walter MJ, Morton JD, Kajiwara N, Agapov E, Holtzman MJ: Viral induction of a chronic asthma phenotype and genetic segregation from the acute response. J Clin Invest 2002, 110(2):165-175.

30. Beigelman A, Gunsten S, Mikols CL, Vidavsky I, Cannon CL, Brody SL, Walter MJ: Azithromycin Attenuates Airway Inflammation in a Noninfectious Mouse Model of Allergic Asthma. Chest 2009, 136(2):498-506.

31. Gunsten S, Mikols CL, Grayson MH, Schwendener RA, Agapov E, Tidwell RM, Cannon CL, Brody SL, Walter MJ: IL-12 p80-dependent macrophage recruitment primes the host for increased survival following a lethal respiratory viral infection. Immunology 2009, 126(4):500-513.

32. Mikols CL, Yan L, Norris JY, Russell TD, Khalifah AP, Hachem RR, Chakinala MM, Yusen RD, Castro M, Kuo E, Patterson GA, Mohanakumar T, Trulock EP, Walter MJ: IL-12 p80 is an innate epithelial cell effector that mediates chronic allograft dysfunction. Am J Respir Crit Care Med 2006 174(4):461-470

33. Russell TD, Yan Q, Fan G, Khalifah AP, Bishop DK, Brody SL, Walter MJ: IL-12 p40 homodimer-dependent macrophage chemotaxis and respiratory viral inflammation are mediated through IL-12 receptor beta 1. $J$ Immunol 2003, 171(12):6866-6874.

34. Hoffmann N, Lee B, Hentzer M, Rasmussen TB, Song Z, Johansen HK, Givskov M, Hoiby N: Azithromycin blocks quorum sensing and alginate polymer formation and increases the sensitivity to serum and stationary-growth-phase killing of Pseudomonas aeruginosa and attenuates chronic $\mathrm{P}$. aeruginosa lung infection in $\mathrm{Cftr}(-/-)$ mice. Antimicrob Agents Chemother 2007, 51(10):3677-3687.

35. Conte JE Jr, Golden J, Duncan S, McKenna E, Lin E, Zurlinden E: Singledose intrapulmonary pharmacokinetics of azithromycin, clarithromycin, ciprofloxacin, and cefuroxime in volunteer subjects. Antimicrob Agents Chemother 1996, 40(7):1617-1622.

36. Bao Z, Lim S, Liao W, Lin Y, Thiemermann C, Leung BP, Wong WS: Glycogen synthase kinase-3beta inhibition attenuates asthma in mice. Am J Respir Crit Care Med 2007, 176(5):431-438.

37. Duan W, Chan JH, Wong CH, Leung BP, Wong WS: Anti-inflammatory effects of mitogen-activated protein kinase kinase inhibitor U0126 in an asthma mouse model. J/mmunol 2004, 172(11):7053-7059.

38. Look DC, Walter MJ, Williamson MR, Pang L, You Y, Sreshta JN, Johnson JE, Zander DS, Brody SL: Effects of paramyxoviral infection on airway epithelial cell Foxj1 expression, ciliogenesis, and mucociliary function. Am J Pathol 2001, 159(6):2055-2069.

39. Sato K, Suga M, Akaike T, Fujii S, Muranaka H, Doi T, Maeda H, Ando M: Therapeutic effect of erythromycin on influenza virus-induced lung injury in mice. Am J Respir Crit Care Med 1998, 157(3 Pt 1):853-857.

40. Asada M, Yoshida M, Suzuki T, Hatachi Y, Sasaki T, Yasuda H, Nakayama K, Nishimura H, Nagatomi R, Kubo H, Yamaya M: Macrolide antibiotics inhibit respiratory syncytial virus infection in human airway epithelial cells. Antiviral Res 2009, 83(2):191-200,

41. Ivetic Tkalcevic V, Bosnjak B, Hrvacic B, Bosnar M, Marjanovic N, Ferencic Z, Situm K, Culic O, Parnham MJ, Erakovic V: Anti-inflammatory activity of azithromycin attenuates the effects of lipopolysaccharide administration in mice. Eur J Pharmacol 2006, 539(1-2):131-138.

42. Leiva M, Ruiz-Bravo A, Jimenez-Valera M: Effects of telithromycin in in vitro and in vivo models of lipopolysaccharide-induced airway inflammation. Chest 2008, 134(1):20-29.

43. Tsai WC, Rodriguez ML, Young KS, Deng JC, Thannickal VJ, Tateda K, Hershenson MB, Standiford TJ: Azithromycin blocks neutrophil recruitment in Pseudomonas endobronchial infection. Am J Respir Crit Care Med 2004, 170(12):1331-1339.

44. Harcourt JL, Karron RA, Tripp RA: Anti-G protein antibody responses to respiratory syncytial virus infection or vaccination are associated with inhibition of $\mathrm{G}$ protein CX3C-CX3CR1 binding and leukocyte chemotaxis. J Infect Dis 2004, 190(11):1936-1940.

45. Zhang W, Choi Y, Haynes LM, Harcourt JL, Anderson LJ, Jones LP, Tripp RA: Vaccination to induce antibodies blocking the CX3C-CX3CR1 interaction of respiratory syncytial virus $\mathrm{G}$ protein reduces pulmonary inflammation and virus replication in mice. J Virol 84(2):1148-1157.

46. Haynes LM, Caidi H, Radu GU, Miao C, Harcourt JL, Tripp RA, Anderson LJ: Therapeutic monoclonal antibody treatment targeting respiratory syncytial virus (RSV) $G$ protein mediates viral clearance and reduces the pathogenesis of RSV infection in BALB/c mice. J Infect Dis 2009, 200(3):439-447.

47. Kawasaki S, Takizawa H, Ohtoshi T, Takeuchi N, Kohyama T, Nakamura H, Kasama T, Kobayashi K, Nakahara K, Morita Y, Yamamoto K: Roxithromycin inhibits cytokine production by and neutrophil attachment to human bronchial epithelial cells in vitro. Antimicrob Agents Chemother 1998, 42(6):1499-1502.

48. Adachi T, Motojima S, Hirata A, Fukuda T, Kihara N, Kosaku A, Ohtake H, Makino S: Eosinophil apoptosis caused by theophylline, glucocorticoids, and macrolides after stimulation with IL-5. J Allergy Clin Immunol 1996, 98(6 Pt 2):S207-215.

49. Hatipoglu $U$, Rubinstein I: Low-dose, long-term macrolide therapy in asthma: An overview. Clin Mol Allergy 2004, 2(1):4

50. Jenkins SG, Farrell DJ: Increase in pneumococcus macrolide resistance, United States. Emerg Infect Dis 2009, 15(8):1260-1264.

doi: 10.1186/1465-9921-11-90

Cite this article as: Beigelman et al., Azithromycin attenuates airway inflammation in a mouse model of viral bronchiolitis Respiratory Research 2010, 11:90 